\title{
Implementasi Kurikulum 2013 Kelas V Sekolah Dasar Negeri Jombor 01
}

\author{
Para Mitta Purbosari $^{1)}$ Koko Prasetyo $^{2)}$ Tri Sutrisno $^{3)}$ \\ 1Program Studi PGSD, Universitas Veteran Bangun Nusantara \\ Email: paramittapurbosari@yahoo.com \\ 2Program Studi PGSD, Universitas Veteran Bangun Nusantara \\ Email: paramittapurbosari@yahoo.com \\ 3Program Studi PGSD, Universitas Veteran Bangun Nusantara \\ Email: paramittapurbosari@yahoo.com
}

\begin{abstract}
Abstrak
Tujuan penelitian ini adalah untuk mengetahui proses implementasi Kurikulum 2013 kelas $\mathrm{V}$ di SDN Jombor 01 Bendosari dilihat dari proses perencanaan, pelaksanaan, penilaian hasil belajar, dan hambatan yang dihadapi guru dalam mengimplementasikan Kurikulum 2013 kelas V di SDN Jombor 01 Bendosari. Penelitian ini menggunakan pendekatan kualitatif yang mengungkapkan makna konseptual dan asosiatif apa adanya. Sumber data penelitian ini diperoleh melalui data primer yang didapat dari hasil wawancara dengan guru kelas VB untuk mengetahui implementasi Kurikulum 2013, sedangkan untuk data sekunder meliputi dokumen-dokumen yang berupa berita atau dokumen lain yang berkaitan dengan pelaksanaan dan hambatan dalam implementasi Kurikulum 2013, serta catatan hasil observasi yang dilakukan. Prosedur pengumpulan data meliputi : teknik wawancara, observasi dan dokumentasi. Prosedur analisis data dalam penelitian ini adalah: Reduksi data, penyajian data, dan verifikasi/ menarikan kesimpulan. Hasil penelitian dapat disimpulkan bahwa Implementasi Kurikulum 2013 dalam kegiatan perencanaan pembelajaran yang dilakukan guru adalah mengkaji silabus, mengkaji buku guru, menyusun RPP dengan menjabarkan langkah kegiatan pembelajaran. Sedangkan dalam pelaksanaan pembelajaran guru menggunakan pendekatan saintifik sesuai dengan Kurikulum 2013 yang meliputi kegiatan mengamati, menanya, mengumpulkan informasi/ mencoba, mengasosiasikan/ menalar, dan mengkomunikasikan (5M). Kegiatan penilaian pembelajaran guru, menggunakan penilaian autentik untuk menilai kompetensi sikap, kompetensi pengetahuan, dan kompetensi keterampilan. Serta hambatan yang dihadapi guru dalam kegiatan perencanaan pembelajaran yaitu dari kondisi siswa sendiri, hambatan saat kegiatan pelaksanaan pembelajaran adalah kurang tersedianya sarana dan prasarana seperti sumber belajar (buku guru dan buku siswa) dan hambatan dalam penilaian pembelajaran adalah guru membutuhkan waktu yang lama untuk melakukan penilaian.
\end{abstract}

Kata kunci : Implementasi, Kurikulum 2013

\begin{abstract}
Abtract
The purpose of this study was to determine the $2013 \mathrm{~V}$ class curriculum implementation process at Jombor 01 Elementary School Bendosari viewed from the process of planning, implementing, evaluating learning outcomes, and the obstacles faced by teachers in implementing $2013 \mathrm{~V}$ grade curriculum at Jombor 01 Elementary School Bendosari. This study uses a qualitative approach that expresses the conceptual and associative meaning as
\end{abstract}


is. Data sources of this study were obtained through primary data obtained from interviews with VB class teachers to determine the implementation of 2013 curriculum, while for secondary data include documents in the form of news or other documents relating to implementation and obstacles in the implementation of 2013 curriculum, as well as notes results of observations made. Data collection procedures include: interview techniques, observation and documentation. Data analysis procedures in this study are: Data reduction, data presentation, and verification / conclusions. The results of the study can be concluded that the 2013 Curriculum Implementation in the learning planning activities conducted by the teacher is reviewing the syllabus, reviewing the teacher's book, preparing the RPP by describing the steps of learning activities. Whereas in the implementation of learning the teacher uses a scientific approach in accordance with the 2013 curriculum which includes observing, questioning, gathering information / trying, associating / reasoning, and communicating $(5 \mathrm{M})$. Teacher learning assessment activities, using authentic assessments to assess attitude competencies, knowledge competencies, and skills competencies. As well as the obstacles faced by teachers in learning planning activities, namely from the condition of the students themselves, the obstacles when implementing learning activities is the lack of availability of facilities and infrastructure such as learning resources (teacher books and student books) and obstacles in learning assessment is that teachers need a long time to assess.

Keywords: Implementation, Curriculum 2013

\section{PENDAHULUAN}

Kurikulum di Indonesia telah mengalami beberapa kali perubahan, perubahan kurikulum yang dilakukan oleh pemerintah adalah dengan tujuan untuk memperbaiki sistem pendidikan. Perubahan dari Kurikulum Berbasis Kompetensi (KBK) menjadi Kurikulum Tingkat Satuan Pendidikan (KTSP) kemudian beralih lagi menjadi Kurikulum 2013. Perubahan Kurikulum 2013 harus disikapi, diantisipasi dan dipahami oleh berbagai pihak karena kurikulum merupakan jembatan dan jantungnya pendidikan yang akan menentukan kualitas pendidikan di Indonesia. Kurikulum 2013 menuntut guru untuk lebih kreatif, inovatif dan memiliki keterampilan. Kurikulum 2013 telah dicanangkan oleh pemerintah terutama oleh Mendikbud tahun 2013 untuk diterapkan di sekolah baik SD, SMP dan SMA/SMK. Kurikulum 2013 telah diimplementasikan sejak tahun ajaran baru 2013/2014 tepatnya bulan Juli tahun 2013 dengan sasaran uji coba pada satuan pendidikan tingkat Sekolah Dasar (SD) kelas I dan IV, Sekolah Menengah Pertama (SMP) kelas VII dan Sekolah Menengah Atas (SMA) kelas IX. Sedangkan pada awal tahun 2014 tahun pelajaran 2014/2015 kurikulum 2013 serentak diberlakukan 
di semua jenjang sekolah, mulai dasar hingga menengah menerapkan Kurikulum 2013. Kesan dipaksankan sangat melekat pada Kurikulum 2013, karena tidak semua sekolah siap untuk melaksanakan, masalah yang timbul diantaranya pelatihan kurikulum 2013 belum merata diberikan kepada seluruh guru yang ada di Indonesia hanya beberapa guru saja dalam satu sekolah yang mengikuti pelatihan Kurikulum 2013, itu pun mengenai Kurikulum 2013 secara umum. Dalam memahami kurikulum 2013 guru membutuhkan waktu yang tidak sedikit ditambah lagi dengan tema dari Kurikulum 2013 yakni tematik-integratif seperti dimana mata pelajaran IPA sebagai mata pelajaran terpadu merupakan integrasi dari berbagai cabang ilmu-ilmu pengetahuan.

Dalam mengimplementasikan Kurikulum 2013 di SDN Jombor 01 Bendosari guru harus kreatif dalam menentukan metode pembelajaran, strategi pembelajaran, dan lainnya sehingga memberikan layanan dan kemudahan belajar bagi peserta didik. Masalah lain yang muncul berupa ketidaksiapan guru dalam melaksanakan kurikulum 2013 dalam proses pembelajaran dan sistem penilaian dalam Kurikulum 2013, karena penilaian pada Kurikulum 2013 menggunakan penilaian autentik dimana guru harus mampu menggambarkan sikap, keterampilan, dan pengetahuan yang sudah atau belum dimiliki oleh peserta didik.

Implementasi Kurikulum 2013 sendiri di daerah Sukoharjo belum sepenuhnya diterapkan di sekolah-sekolah dasar akan tetapi Sekolah Dasar Negeri Jombor 01 sudah menerapkan dan mengimplementasikan Kurikulum 2013 dalam pembelajaran. Pada hari Rabu tanggal 1 Februari 2017, dilakukan wawancara dengan Kepala SD Negeri Jombor 01 Sukoharjo, Bapak Sarimin. Berdasarkan wawancara tersebut didapatkan informasi bahwa SD Negeri Jombor 01 Sukoharjo merupakan salah satu Sekolah Dasar di daerah Kabupaten Sukoharjo yang ditunjuk pemerintah sebagia sekolah yang mengimplementasikan Kurikulum 2013. Sekolah Dasar Negeri Jombor 01 Sukoharjo memiliki 12 kelas yang terdiri dari kelas 1 sampai kelas 6 dan masing-masing kelas dibuat secara paralel menjadi 2 kelas. Bagaimana implementasi Kurikulum 2013 dalam perencanaan, pelaksanaan dan penilaian pembelajaran, serta apa hambatan yang dihadapi guru saat mengimplementasikan Kurikulum 2013 dalam pembelajaran kelas V di SD Negeri 
Jombor 01 Bendosari tahun pelajaran 2016/2017 menjadi hal yang dapat di jadikan bahan pertimbangan dan perbaikan pembelajaran selanjutnya.

\section{METODE PENELITIAN}

Penelitian ini menggunakan pendekatan kualitatif karena data yang disajiakan berupa kata-kata. Sumber data primer dalam penelitian ini didapat melalui wawancara dengan guru kelas V B untuk mengetahui implementasi Kurikulum 2013, sedangkan dalam proses perencanaan pembelajaran, data tersebut didapatkan melalui dokumentasi yang berupa silabus dan rencana pelaksanaan pembelajaran (RPP), serta wawancara dengan kepala sekolah untuk mengetahui implementasi Kurikulum 2013 secara umum, pelaksanaan pengawasan proses pembelajaran, dan hambatan yang dialami kepala sekolah dalam implementasi Kurikulum 2013. Sumber data sekunder yang gunakan berupa dokumen-dokumen sekolah, RPP, Silabus dan foto sebagai dokumentasi. Teknik analisis data menggunakan model Miles dan Hubermen. Aktivitas dalam analisis data, yakni data reduction (reduksi data), data display (penyajian data) dan conclusion drawing/verification (penarikan kesimpulan dan verifikasi).

\section{HASIL DAN PEMBAHASAN}

a. Implementasi Kurikulum 2013 dalam perencanaan, pelaksanaan dan penilaian pembelajaran.

1) Perencanaan Pembelajaran

Tahap pertama dalam pembelajaran adalah perencanaan pembelajaran merupakan kegiatan memproyeksikan tindakan apa yang akan dilaksanakan dalam suatu kegiatan belajar mengajar yang diwujudkan dengan kegiatan mengkoordinasikan (mengatur dan merespon) komponen-komponen pembelajaran, sehingga arah kegiatan (tujuan), isi kegiatan (materi), cara penyampaian kegiatan (metode dan teknik), serta bagaimana mangukurnya (evaluasi) menjadi jelas dan sistematis atau kegiatan penyusunan Rencana Pelaksanaan Pembelajaran atau RPP (Sudjana, 1998 : 48). Berdasarkan hasil penelitian, guru membuat RPP 
selama satu semester dengan acuan silabus yang disusun oleh pemerintah, sehingga guru tidak setiap hari membuat RPP sebelum mengajar.

Berikut ini adalah tabel kegiatan perencanaan pembelajaran yang dilakukan oleh guru.

Tabel 1. Kegiatan Perencanaan Pembelajaran

\begin{tabular}{ll}
\hline Kegiatan Perencanaan & \multicolumn{1}{c}{ Kegiatan Guru } \\
\hline Mengkaji Silabus & $\begin{array}{l}\text { Guru mengkaji silabus dengan mencermati KI dan } \\
\text { KD pada silabus yang sudah di susun oleh Pusat. }\end{array}$
\end{tabular}

Mengkaji Buku Guru Guru mengkaji buku guru dengan mencermati KI dan KD pada buku.

Menyusun RPP

Guru menyusun RPP menggunakan buku guru sebagai acuan, termasuk dalam menjabarkan langkah-langkah kegiatan pembelajaran.

Berdasarkan tabel diatas, kegiatan perencanaan pembelajaran yang dilakukan oleh guru adalah mengkaji silabus, mengkaji buku guru, dan menyusun RPP. Hal ini sudah sesuai dengan pembelajaran Kurikulum 2013. Silabus yang digunakan guru adalah silabus tematik Kurikulum 2013 dari pemerintah. Guru mengkaji silabus dan buku guru dengan mencermati KI dan KD pada silabus dan buku guru. Sebelum melaksanakan proses pembelajaran, terlebih dahulu guru membuat perangkat pembelajaran berupa RPP. Berdasarkan hasil wawancara, dapat diketahui bahwa guru membuat RPP sendiri dan telah diketahuai serta di tanda tangani oleh kepala sekolah.

2) Pelaksanaan Pembelajaran

Guru melakukan pembelajaran seperti yang sudah direncanakan dalam RPP, akan tetapi dalam proses pembelajaran masih terdapat pembelajaran yang berbasis KTSP. Dari hasil wawancara tersebut dapat diketahui bahwa guru melaksanakan pembelajaran sesuai dengan RPP yang sudah di susun, 
walaupun masih ada materi pembelajaran yang belum tersampaikan karena alokasi waktu yang tidak mencukupi. Sebelum pelaksanaan pembelajaran guru juga mengawali dengan mengajak berdoa dan membahas sedikit materi pelajaran yang sudah di pelajari sebelumnya. Saat proses pembelajaran pun guru juga memberikan pembelajaran yang menyenangkan, sehingga peserta didik mudah menerima dan bisa memahami pelajaran yang disampaikan oleh guru. Sekolah juga memberikan dukungan fasilitas untuk membantu proses pelaksanaan pembelajaran. Dalam proses penyampaian pelajaran masih terdapat menggunakan kurikulum KTSP. Dari hasil observasi dan wawancara dengan kepala sekolah, dapat diketahui bahwa sekolah memberi dukungan berupa fasilitas yang antara lain adalah buku guru, buku siswa, alat peraga, computer, jaringan internet dan ruang perpustakan. Selanjutnya, berdasarkan hasil observasi dan wawancara pelaksanaan pembelajaran dalam Kurikulum 2013 yang dilakukan oleh guru terdiri dari 3 kegiatan utama yaitu kegiatan pendahuluan, kegiatan inti, dan kegiatan penutup.

\section{Kegiatan Pendahuluan}

Berdasarkan hasil observasi, kegiatan pembelajaran yang dilakukan oleh guru dalam kegiatan pendahuluan antara lain adalah mengkondisikan suasana kelas yang menyenangkan, menyampaikan kompetensi yang akan dicapai, menyampaikan garis besar cakupan materi dan menyampaikan lingkup dan teknik penilaian yang digunakan.

\section{Kegiatan Inti}

Berdasarkan hasil observasi, wawancara dan dokumentasi diperoleh data bahwa kegiatan inti yang dilakukan guru menonjolkan kegiatan 5M. Kegiatn 5M dalam Pendekatan Saintifik meliputi kegiatan mengamati, menanya, mengumpulkan informasi / mencoba, mengasosiasi / menalar, dan mengkomunikasikan. Implikasi Kurikulum 2013 guru dalam menyampaikan pembelajaran tidak hanya menggunakan metode ceramah akan tetapi menggunakan metode yang sesuai dengan materi yang di ajarkan, begitupun juga dengan media/alat peraga, dalam pembelajaran 
IPA guru juga menggunakan alat peraga sebagai alat untuk mendukung penyampaian pelajaran. Penggunaan media/alat peraga sesuai dengan materi yang sedang diajarkan. Seperti contoh dalam pelajaran IPA materi Kerangka manusia dan hewan guru menggunakan media/ alat peraga buku guru dan alat peraga berupa kerangka manusia.

\section{Kegiatan Penutup}

Berdasarkan hasil observasi, dalam kegiatan penutup guru melaksanakan kegiatan seperti membuat rangkuman/simpulan pelajaran, melakukan refleksi, memberikan umpan balik, melakukan penilaian, merencanakan kegiatan tindak lanjut dan menyampaikan rencana pembelajaran pada pertemuan berikutnya. Guru juga berusaha membimbing siswa untuk menyimpulkan / merangkum pelajaran yang sudah dilakukan dengan cara melakukan tanya jawab dengan siswa. Guru melakukan refleksi dengan cara menanyakan kepada siswa tentang kegiatan apa saja yang sudah dilakukian oleh siswa. Guru juga memberi umpan balik terhadap proses dan hasil pembelajaran dengan cara memberi penguatan kepada siswa tentang materi yang sudah dipelajari.

3) Penilaian Pembelajaran

Setelah pelaksanaan pembelajaran, tahap selanjutnya yaitu penilaian pembelajaran.

Tabel 2. Pelaksanaan Penilaian Autentik dalam pembelajaran Tema 6 Subtema 1 pembelajaran 2

\begin{tabular}{|c|c|c|}
\hline No & Indikator & Deskripsi Hasil Temuan \\
\hline 1. & Menggunakan pedoman penskoran & $\begin{array}{l}\text { Guru menggunakan } \\
\text { pensekoran dalam menilai } \\
\text { seperti skor } 4=\text { baik sekali, } \\
3=\text { baik, } 2=\text { cukup baik, } 1= \\
\text { perlu bimbingan. }\end{array}$ \\
\hline & \multicolumn{2}{|c|}{ Penilaian Kompetensi Sikap } \\
\hline 2. & $\begin{array}{l}\text { Menggunakan penilaian diri, penilaian } \\
\text { antar siswa, pengamatan/observasi }\end{array}$ & $\begin{array}{l}\text { Guru menggunakan } \\
\text { penilaian diri untuk menilai } \\
\text { sikap siswa melalui } \\
\text { pengamatan. }\end{array}$ \\
\hline
\end{tabular}




\begin{tabular}{|c|c|c|}
\hline No & Indikator & Deskripsi Hasil Temuan \\
\hline 3. & $\begin{array}{l}\text { Instrument yang digunakan antara lain } \\
\text { daftar cek atau skala penilaian yang } \\
\text { disertai dengan }\end{array}$ & - \\
\hline \multicolumn{3}{|c|}{ Penilaian Kompetensi Pengetahuan } \\
\hline 4. & $\begin{array}{l}\text { Guru menilai kompetensi pengetahuan } \\
\text { melalui tes tertulis, tes lisan, dan } \\
\text { penugasan }\end{array}$ & $\begin{array}{l}\text { Guru menggunakan tes } \\
\text { tertulis untuk menilai } \\
\text { pengetahuan siswanya }\end{array}$ \\
\hline 5 & $\begin{array}{l}\text { Instrumen tertulis : berupa soal pilihan } \\
\text { ganda, isian, jawaban singkat, benar- } \\
\text { salah, menjodohkan, dan uraian. }\end{array}$ & $\begin{array}{l}\text { Instrument tes berupa isian } \\
\text { berjumlah } 10 \text { soal yang } \\
\text { diambil dari buku siswa }\end{array}$ \\
\hline 6. & $\begin{array}{l}\text { Instrument tes lisan : berupa daftar } \\
\text { pertanyaan yang diberikan oleh guru } \\
\text { secara ucapan sehingga siswa merespon } \\
\text { pertanyaan tersebut, dan menimbulkan } \\
\text { keberanian dari siswa. Jawaban dapat } \\
\text { berupa kata, frase, kalimat atau } \\
\text { paragraph yang diharapkan. }\end{array}$ & $\begin{array}{l}\text { Instrumen tes lisan berupa } \\
\text { soal yang diucapkan secara } \\
\text { spontan oleh guru }\end{array}$ \\
\hline 7. & $\begin{array}{l}\text { Instrument penugasan: berupa pekerjaan } \\
\text { rumah yang dikerjakan secara individual } \\
\text { atau kelompok sesuai dengan } \\
\text { karakteristik tugas. }\end{array}$ & $\begin{array}{l}\text { Instrumen penugasan, guru } \\
\text { memberikan pekerjaan } \\
\text { rumah kepada siswa dan } \\
\text { dikerjakan secara individual }\end{array}$ \\
\hline \multicolumn{3}{|c|}{ Penilaian Kompetensi Keterampilan } \\
\hline 8. & Menggunakan penilaian kinerja & $\begin{array}{l}\text { Menggunakan penilaian } \\
\text { kinerja untuk menilai } \\
\text { keterampilan siswa dalam } \\
\text { membuat pertanyaan. }\end{array}$ \\
\hline 9. & Menggunakan penilaian proyek & - \\
\hline
\end{tabular}

Berdasarkan hasil observasi, guru melakukan kegiatan penilaian dalam proses pembelajaran menggunakan pendekatan saintifik dengan penilaian autentik. Dari hasil wawancara tersebut, guru melakukan penilaian yang meliputi ranah sikap, pengetahuan dan keterampilan siswa, hal ini sudah sesuai dengan Penilaian Autentik dalam Kurikulum 2013. Dalam penilaian pada akhir semester atau penilaian hasil belajar siswa di Sekolah Dasar Negeri Jombor 01 menggunakan sistem aplikasi yang sudah di buat dari sekolah yang sudah termasuk dalam Kurikulum 2013, Penjelasan lebih lanjut untuk penilaian sikap, pengetahuan, dan keterampilan yang dilakukan guru adalah sebagai berikut: 
1) Penilaian Sikap

Berdasarkan hasil observasi, guru melakukan penilaian sikap selama proses pembelajaran melalui pengamatan. Sikap siswa yang dinilai adalah taat beribadah, bersyukur, berdoa, toleransi, dan kekhusukan dalam berdoa untuk KI-1. Sedangkan untuk KI-2 sikap yang dinilai adalah tanggung jawab, teliti, santun, percaya diri, kerjasama, disiplin, dan jujur.

2) Penilaian Pengetahuan

Berdasarkan hasil observasi, guru menggunakan tes tertulis, tes lisan dan penugasan untuk menilai pengetahuan siswa. Berdasarkan hasil observasi untuk tes tertulis yang digunakan guru berupa soal isian, jawaban singkat dan uraian, soal isian dan jawaban singkat berasal dari buku siswa, untuk tes lisan guru memberikan pertanyaan-pertanyaan yang sifatnya memancing siswa untuk menjawab, sedangkan untuk tes penugasan guru membarikan pekerjaan rumah (PR) secara individu kepada siswa.

3) Penilaian Keterampilan

Berdasarkan hasil observasi, guru menggunakan penilaian kinerja untuk menilai keterampilan siswa, guru menilai keterampilan siswa dalam membuat pertanyaan selain itu guru juga menilai keterampilan siswa dalam menunjukkan nama bagian organ tubuh manusia dan funsinya secara benar. Dalam kegiatan penilaian pembelajaran guru sudah menggunakan penilaian autentik. Guru menilai sikap siswa melalui pengamatan, pengetahuan dengan soal tes tertulis, tes lisan dan penugasan serta keterampilan menggunakan penilaian kenerja.

b. Hambatan yang dihadapi saat mengimplementasikan Kurikulum 2013 mata pelajaran IPA kelas V B

Berdasarkan hasil wawancara dan observasi pada saat pelaksanaan pembelajaran Kurikulum 2013 di kelas V SDN Jombor 01 Bendosari, ditemukan 
beberapa hambatan. Berikut ini adalah tabel hambatan yang dihadapi guru saat mengimplementasikan Kurikulum 2013 mata pelajaran IPA di kelas V mulai dari hambatan perencanaan pembelajaran, hambatan pelaksanaan pembelajaran, dan hambatan penilaian pembelajaran.

1) Hambatan dalam Perencanaan Pembelajaran

Hambatan yang ditemui guru dalam perencanaan pembelajaran yaitu dari kondisi siswa sendiri, perubahan pembelajaran dari pembelajaran yang berbasis KTSP menjadi Kurikulum 2013 menimbulkan kebingungan/ belum bisa sepenuhnya menerapkan pembelajaran yang berbasis Tematik. Berdasarkan hasil wawancara hambatan perencanaan pembelajaran yaitu dari kondisi siswa sendiri, karena pergantian Kurikulum 2013 tidak langsung bisa diterapkan secara baik oleh siswa, jadi guru membimbing siswa dalam proses pembelajaran.

2) Hambatan dalam Pelaksanaan Pembelajaran

Hambatan yang ditemui guru dalam pelaksanaan pembelajaran yaitu dari sarana dan prasarana seperti sumber belajar (buku guru dan buku siswa), sebelumnya sekolah menggunakan KTSP dan pada tahun 2013 berubah menggunakan Kurikulum 2013 sehingga sumber belajar yang tersedia belum lengkap.

3) Hambatan dalam Penilaian Pembelajaran

Hambatan yang dihadapi guru dalam penilaian pembelajaran yaitu banyaknya aspek yang dinilai karena pembelajaran termasuk dalam penilaian Kurikulum 2013, sehingga membutuhkan waktu yang lama untuk melakukan penilaian.

\section{SIMPULAN}

Guru sudah merencanakan kegiatan pembelajaran. Kegiatan perencanaan pembelajaran IPA yang dilakukan guru adalah mengkaji silabus, mengkaji buku guru, menyusun RPP dengan menjabarkan langkah kegiatan pembelajaran. Sedangkan dalam pelaksanaan pembelajaran guru menggunakan pendekatan saintifik sesuai dengan Kurikulum 2013 yang meliputi kegiatan mengamati, 
menanya, mengumpulkan informasi/ mencoba, mengasosiasikan/ menalar, dan mengkomunikasikan $(5 \mathrm{M})$. Penilaian pembelajaran guru menggunakan penilaian autentik untuk menilai kompetensi sikap, kompetensi pengetahuan, dan kompetensi keterampilan. Hambatan yang dihadapi guru saat mengimplementasikan Kurikulum 2013 dalam kegiatan perencanaan pembelajaran yaitu dari kondisi siswa sendiri, siswa masih belum bisa sepenuhnya menerapkan pembelajaran yang berbasis Tematik, sedangkan hambatan saat kegiatan pelaksanaan pembelajaran adalah kurang tersedianya sarana dan prasarana seperti sumber belajar (buku guru dan buku siswa) dikarenakan perubahan Kurikulum dari KTSP menjadi Kurikulum 2013 sehingga sumber belajar pun tidak langsung tersedia. Hambatan dalam penilaian pembelajaran adalah banyaknya aspek yang harus dinilai dalam penilaian Kurikulum 2013, sehingga guru membutuhkan waktu yang lama untuk melakukan penilaian.

Dalam mengimplementasikan Kurikulum 2013 hendaknya Pemerintah Dinas Pendidikan Kota Sukoharjo perlu meningkatkan lagi kegiatan sosialisasi Kurikulum 2013 secara merata pada tiap sekolah. Kelengkapan dan ketersediaan buku pembelajaran (Buku guru dan siswa) untuk segera didistribusikan pada tiap sekolah agar proses pelaksanaan pembelajaran dapat berjalan dengan lancar. Bagi kepala sekolah hendaknya melakukan monitoring dan pelatihan terhadap pelaksanaan pembelajaran dan penilaian dalam Kurikulum 2013 untuk meningkatkan kemampuan guru dalam mengimplementasikan Kurikulum 2013.

\section{DAFTAR PUSTAKA}

Abdul Majid. 2014. Implementasi Kurikulum 2013. Bandung: interes media.

Ahmad Susanto. 2013. Teori Belajar \& Pembelajaran di Sekolah Dasar. Jakarta: Prenada media Group.

E Mulyasa. 2013. Pengembangan dan Implementasi Kurikulum 2013. Bandung :PT Remaja Rosda karya.

Erlinawati. 2015. Skripsi Implementasi Kurikulum 2013 mata pelajaran IPS Kelas VII Di SMP N 6 Magelang. Skripsi : Pendidikan Guru Sekolah Dasar, Fakultas Ilmu Pendidikan. Universitas Negeri Semarang. 
Fadlillah, M.2014. Implementasi Kurikulum 2013 Dalam Pembelajaran SD/MI, SMP/MTS. \& SMA/MA. Yogyakarta: Ar-ruzz Media.

Hasan Basri. 2015. Paradigma Baru Sistem Pembelajaran. Bandung: CV Pustaka Setia.

Kemdikbud. 2013. Permendikbud No 54 tahun 2013 tentang Standar Kompetensi Lulusan. Jakarta: Kemdikbud.

Kemdikbud. 2013. Permendikbud No 65 tahun 2013 tentang Standar Proses. Jakarta: Kemdikbud.

Kemdikbud. 2013. Permendikbud No 66 tahun 2013 tentang Standar Penilaian. Jakarta: Kemdikbud.

Kemdikbud. 2013. Permendikbud No 67 tahun 2013 tentang Kerangka Dasar dan Struktur Kurikulum Sekolah Dasar/Madrasah Ibtidaiyah. Jakarta: Kemdikbud.

Kemdikbud. 2013. Permendikbud RI No 81A tahun 2013 Tentang Implementasi Kurikulum. Jakarta: Kemdikbud.

Lexy J. Moleong. 2007. Metodologi Penelitian Kualitatif. Bandung: PT Remaja Rosda Karya.

Nana Sudjana. 1997. Penilaian Hasil Proses Belajar Mengajar. Bandung: Rosda Karya.

Soegiyono. 2013. Memahami Penelitian Kualitatif. Bandung: Alfabeta

Sholeh Hidayat. 2013. Pengembangan Kurikulum Baru. Bandung: PT Remaja Rosda karya.

Suharta, Gilang Pramada. 2014. Skripsi Pelaksanaan Uji Coba Implementasi Kurikulum 2013 di Sekolah Dasar Negeri Bantul Timur. Skripsi: Pendidikan Guru Sekolah Dasar, Fakultas Ilmu Pendidikan. Universitas Negeri Yogyakarta.

Vebri Kurniawati A.M, Eka. 2014. Skripsi Implementasi kurikulum 2013 di kelas IV B SD N 4 Wates Kabupaten Kulon Progo. Skripsi: Pendidikan Guru Sekolah Dasar, Fakultas Ilmu Pendidikan. Universitas Negeri 